\title{
South African studies: a review of NISC's anthology CD-ROM
}

\author{
Ina Fourie* \& Shirley J. Behrens \\ Department of Information Science, University of South Africa, P.O. Box 392, Pretoria, 0001 Republic of South Africa \\ fourii@alpha.unisa.ac.za \& behresj@alpha.unisa.ac.za
}

Received March 1997; accepted March 1997

\begin{abstract}
South African studies is an anthology CD-ROM containing a suite of 11 South African databases (including the South African national bibliography and the Index to South African periodicals) which are integrated on one disc. The first edition appeared early in 1996; the CD-ROM is updated quarterly and published by National Inquiry Services Centre (NISC) South Africa. A general description of South African studies is given and the product is evaluated according to specified criteria, namely vendor and product details, technical aspects, the user interface and user friendliness, searching and search management, and output. Although product features and characteristics are considered, the emphasis is placed on user interaction and the effectiveness of the software in supporting information retrieval.
\end{abstract}

South African studies is 'n saamgestelde CD-ROM wat 11 Suid-Afrikaanse databasisse op een skyf integreer (insluitende Suid-Afrikaanse nasionale bibliografie en Repertorium van Suid-Afrikaanse tydskrifartikels). Die eerste uitgawe het in 1996 verskyn. Die CD-ROM word kwartaalliks opdateer en word deur National Inquiry Services Centre (NISC) SuidAfrika gepubliseer. 'n Algemene beskrywing van South African studies word gegee en die produk word geëvalueer volgens spesifieke kriteria, naamlik die makelaar- en produkbesonderhede, tegniese aspekte, die gebruikerskoppelvlak en gebruikersvriendelikheid, soektogte en behartiging van soektogte en uitvoer. Alhoewel produkkenmerke oorweeg word, val die klem op gebruikersinteraksie en die effektiwiteit van die programmatuur in die ondersteuning van inligtingherwinning.

*Author to whom correspondence should be addressed.

\section{Background}

South African studies, published by National Inquiry Services Centre (NISC) South Africa, is an anthology CD-ROM containing a suite of 11 South African bibliographic and full-text databases which are integrated on one disc.

NISC SA opened in Grahamstown in May 1995. It is affiliated to the National Information Services Corporation (also NISC), a CD-ROM publishing company with headquarters in Baltimore in the United States of America. NISC SA markets, stocks and supplies all products produced by NISC worldwide, provides updates and offers local technical support. NISC has over 100 bibliographic and full-text databases in its stable (including for example ERIC, Family studies database, GeoSEARCH, PsycLIT and Sociofile). However, most of NISC's databases cover highly specialized fields where there is a small niche market, and the company is well known for its anthology CD-ROMs. The first South African database to be published by NISC was FISHLIT, a bibliographic database maintained by the J.L.B. Smith Institute of Ichthyology Library at Rhodes University in Grahamstown (Crampton 1995). The FISHLIT database is now included on the anthology CD-ROM Fish and fisheries worldwide which is today published by NISC SA. Other anthology CD-ROMs published by NISC SA are Water resources worldwide, African studies, and the CD-ROM under review here, South African studies.

South African studies was published for the first time in early 1996, and is updated quarterly. It uses the ROMWRIGHT $^{\mathrm{TM}}$ software which is standard on all NISC discs.

\section{Purpose of the article}

The intention of this article is to critically review South African studies. The review will cover inter alia the NISC retrieval software, the user interface, various technical aspects, characteristics of anthology databases, and some factors relating to the specific databases. An in-depth evaluation of the retrieval effectiveness of the individual databases will not be attempted. The review is based on the 1987November 1996 edition of the South African studies CDROM and the November 1993 NISC DISC user's guide and the June 1995 Supplement.

\section{Guidelines for critical reviews}

Since the advent of CD-ROM databases in the mid-1980s, numerous reviews and evaluations have been published, but there is less literature on evaluation criteria and CD-ROM standards. Some reviewers focus on the database content and structure, while others emphasize the retrieval software, user interface or technical aspects.

Diverse lists of evaluation criteria and evaluation approaches have been proposed for CD-ROMs. It is generally recognized that most of the principles applying to the evaluation of print-based reference sources should be covered, but these should be supplemented by more specific aspects. Analyses in this regard include the work of Bosch and HancockBeauliey (1995), Harry and Oppenheim (1993a, 1993b), Nicholls (1993), Richards (1995), Richards and Robinson (1993), Rowley (1993; 1995), Schwartz (1993), Snyman (1993), Speight (1996) and Válas (1994). 
Various reviewers have stressed different approaches. Herther (1988), for example, looks at the issue from a collection development point of view. Miller (1987) stresses three perspectives for evaluation, namely descriptive evaluation, comparative evaluation and use evaluation. There is also the consistency-driven approach of Duszak and Koczkodaj (1994). Recently emphasis has been on database quality (Armstrong 1995; Johnston 1994), currency of information (Maes 1995), and special criteria for graphical user interfaces (GUIs) (Bosch \& Hancock-Beauliey 1995; Rowley 1995). Database quality and currency will not be dealt with in detail in this article, since this reflects rather on the producers (i.e. the compilers) of the individual databases. Reviewers are warned against serious omissions and uncritical reviews (Johnston 1994:380; Richards \& Robinson 1993:92) and against focussing on single aspects. According to Válas (1994: 211) most of the earlier reviews focus on the user interfaces and not on the software as a whole.

In this article vendor-related aspects, technical aspects, the user interface and search characteristics will be considered in particular. Our evaluation of South African studies looks at product features and characteristics, but considers especially the issue of user interaction and the effectiveness of the software in supporting information retrieval. For a review such as this, research on evaluation criteria and reviews of other CDROMs can be taken as point of departure (e.g. Andrews 1990; Clement 1994; Foulds \& Foulds 1990; Hartley 1989; Sievert \& Sievert 1991; Van der Merwe 1993). ERIC, LISA, Library literature and Trade and industry ASAP include CD-ROM reviews. Several Internet listservs can be consulted as well; these include PACS-L (address subscriptions to LISTSERV
@UHUPVM1.BITNET), CDROMLAN (address subscriptions to LISTSERV@idbsu.idbsu.edu) and CDROML (address subscriptions to LISTSERV@UCCVMA.UCOP.EDU) (Johnson 1991).

The criteria model of Harry and Oppenheim (1993a, 1993b) was selected as the main point of departure for this article. Where the authors considered it necessary, these criteria were supplemented from other models, notably those of Fourie (1993), Haar et al. (1990), Nicholls et al. (1990), Nicholls (1993), Richards (1995), Richards and Robinson (1993), Schwartz (1993), Snyman (1993), Válas (1994), Van der Walt and Van Brakel (1991) and Van Stuywenberg (1993). Some of these models are based on checklists, whilst others propose ratings or scoring. This article is based on a checklist approach, the authors agreeing with Válas (1994:211) that numeric ranks should not be given, since diverse users have distinct precedences and would thus give different weights when evaluating. The main criteria which were applied in evaluating South African studies are listed in Table 1.

Harry and Oppenheim (1993a:213-214; 1993b:339) suggest that the analysis of a CD-ROM should be accomplished in less than four hours, but the authors found this suggested time unrealistic. Apart from needing to identify a suitable approach and relevant criteria, as reviewers of South African studies we had to become acquainted with the NISC software, formulate suitable search strategies, and double check search results.

\section{Vendor and product details}

South African studies is published by the National Inquiry Services Centre (Pty) Ltd (NISC SA), P.O. Box 377,

\begin{tabular}{|c|c|c|c|c|c|}
\hline $\begin{array}{l}\text { Vendor and } \\
\text { product details }\end{array}$ & $\begin{array}{l}\text { Technical } \\
\text { aspects }\end{array}$ & $\begin{array}{l}\text { User interface (including } \\
\text { user friendliness) }\end{array}$ & $\begin{array}{l}\text { Searching and search } \\
\text { management }\end{array}$ & Output & $\begin{array}{l}\text { Database } \\
\text { contents }\end{array}$ \\
\hline Vendor particulars & Hardware & Introductory screens & Different search modes & Display & Coverage \\
\hline Databases & Software & Screen layout & Boolean and other & Sorting & Completeness \\
\hline Test/demo disc & Installation & Search modes & operators & Print & Currency \\
\hline Update frequency & Manual & Online help & Truncation & Downloading & Quality \\
\hline Equivalents & & User control & Phrase searching & Marking & Indexing policy \\
\hline Licensing & & Response time & Range searching & & Database description \\
\hline Networking & & Directions and error & Nesting & & \\
\hline Subscription fee & & messages & Field limiting/searching & & \\
\hline \multirow[t]{6}{*}{ Reliability } & & Navigation & Search terms & & \\
\hline & & Availability of documents & Browsing & & \\
\hline & & & Editing search statements & & \\
\hline & & & Saving search strategies & & \\
\hline & & & Updating searches & & \\
\hline & & & Duplicate detection & & \\
\hline
\end{tabular}


Grahamstown, 6140 South Africa (telephone: 0461-29698, fax: 0461-29550, internet: NISC@ru.ac.za. - these numbers and addresses are also used as the help line for South African studies).

The databases included in this anthology are:

- Index to South African periodicals (ISAP) (1987+)

ISAP is an index to over 440 South African general periodicals and subject journals. It is a project of the State Library in Pretoria, with indexing for special disciplines contracted out to several institutions and individuals.

- South African national bibliography (SANB) (1988+)

The $S A N B$ is the current national bibliography of South Africa. It is compiled by the State Library from legal deposit records which include books, government publications, pamphlets of over five pages, technical reports, periodicals, newspapers, maps, CD-ROMs, microforms and specifications of the South African Bureau of Standards.

- Index to South African theses and dissertations (1918+)

The Library of the Potchefstroom University for Christian Higher Education compiles this bibliography of theses and dissertations.

- Knipkat (1994+)

This index to press cuttings from newspapers and periodicals covers the Afrikaans language, literature and culture. It is compiled by the Nasionale Afrikaanse Letterkundige Museum en Navorsingsentrum (NALN) in Bloemfontein.

- NELM databases (comprehensive from 1990+, with retrospective indexing underway)

Several bibliographic databases of the National English Literary Museum (NELM) in Grahamstown make up this database, namely Select index to South African literature in English, Critical writings; Select index to South African literature in English, Creative writings; NELM main catalogue; Manuscripts; Literary awards.

- Investor's guide (current)

This full-text database provides details on over 600 companies which are listed on the Johannesburg Stock Exchange. It is compiled by Investors' Group (Pty) Ltd in Johannesburg.

- Witwatersrand University management research reports (1970+)

The Library of Management of the University of the Witwatersrand compiles this database listing research reports of master's students of the Graduate School of Business Administration.

As with all NISC discs, South African studies is available on a 30-day free trial basis. The disc is updated quarterly. Since this is an anthology database, there is no exact equivalent of South African studies in another format, that is where all the databases are available together in one product. However, individual databases are available in other formats from or at their producers, and some are available via SABINET Online. For example, the SANB (1988+ on the NISC disc) dates back to 1959 and is available in printed and electronic format from the State Library; ISAP (1987+ on the
NISC disc) dates back to 1900 and is available in various formats (original cards, print and microfiche); both ISAP and $S A N B$ are also available via SABINET Online.

Subscription to South African studies requires signature of NISC's licence agreement. Licenced discs must be destroyed or returned upon receipt of the update or if the subscription is cancelled. The database can be used on LANs and WANs, with the network fee structure based on concurrent-user access permissions and not on the total number of network stations.

The annual subscription to South African studies is R4101. There is no extra charge for LAN installations which are restricted to single-user access. For two to ten, 11-20 and 2135 concurrent users, the LAN pricing is $+50 \%,+100 \%$ and $+150 \%$ of the basic subscription respectively. The software will ensure that the licensed number of users is adhered to.

NISC has been publishing CD-ROM databases since 1988 and has a good reputation on the international market, with NISC companies in many countries and agents worldwide. South African studies thus has solid backing, including NISC's experienced programming team which developed and continually improves its unique ROMWRIGHTTM software. NISC SA provides friendly and prompt service and has proved very responsive to the needs of its customers.

Of necessity with this type of anthology, NISC SA is completely dependent on the producers of the various databases on South African studies for reliability with regard to the contents of the databases (e.g. scope and extent of documents indexed, suitability of indexing terms, standardization, language of the database, timeliness, and correctness of entries). For example, inaccurate data input is the fault of the producer, not the publisher; likewise the inadequate allocation of indexing terms. On the whole, though, the databases on South African studies are reliable and, being indigenous, are more specific and responsive to local information needs.

\section{Technical aspects}

NISC discs are DOS-based. They can be run on a $286 \mathrm{PC}$, but 386 or greater is recommended to enjoy full advantage of the search engine. Although both colour and monochrome monitors can be used, certain features (e.g. highlighting when displaying records) do not come across acceptably on a monochrome screen. Any CD-ROM drive can be used. South African studies requires at least $2 \mathrm{MB}$ of available hard disk space and $512 \mathrm{k}$ RAM available after booting.

Initial installation of the CD-ROM is simple. Software is on the disc itself. For update discs, the new disc will auto-install itself when there is no software update involved.

South African studies relies on the general NISC DISC User's guide which accompanies all NISC discs. Users often turn first to the documentation accompanying an electronic product, and this manual is not particularly user-friendly. The supplement (of 31 pages) is poorly bound with the main manual (of 180 pages). There is a detailed table of contents for the main manual and a brief contents for the supplement, but the index refers only to the main manual. Additional 
entries in the index would be welcome, especially for more common terms (providing cross-references to NISC's chosen terminology) likely to be used by inexperienced searchers. The 1993 manual and its supplement are being updated by a new edition due in 1997.

\section{User interface}

Nicholls et al. (1990:41) explain that the retrieval engine and the user interface together form the access software of a CDROM product, and that the actual database is that which is accessed. User interfaces are expected to be 'user friendly' a concept which is problematic to define. Trenner (1987:105) suggests that a user-friendly computer system allows all users 'to perform desired tasks without frustration and provides a range of features and functions which help each individual user to optimize his, or her, efficiency', and it is this meaning which has directed our evaluation.

Aspects relating to the user interface thus include different modes of access, user control, the quality of instructions and error messages and navigation through the program and search results. The indication of library holdings and information on document delivery also affect users. Vickery and Vickery (1993) point out several other aspects with regard to the user interface.

The introductory screens of a CD-ROM are important as this is where the user meets the software for the first time. The opening screen of South African studies has a boxed description of the coverage of the database (F1 will move you to another screen with more details on the 11 databases). The opening screen also indicates the search mode; novice is the default, but a message tells you that by pressing the space bar, you can switch modes. Other useful options here include F2 (which provides a full listing of other NISC databases with a brief description of each; $\mathrm{F} 1$ from this screen provides more detail on the selected database, often including a list of the journals indexed for that database), Escape to exit, and Enter to start the disc. This is a simple and successful first screen. The second screen (upon pressing Enter) indicates the time span of the edition, and contains brief details about NISC, licencing and copyright details; by pressing Enter you are brought to the third screen, where you can start searching. Thus the route into the search screen is quick and uncomplicated, but with options for more detail on the way there. The screen layout and the use of colour are good, for example the screens are not too full, they have a variety of boxed divisions, and desktop colours differ for the different search modes.

NISC discs provide three search levels, namely the novice, advanced and expert modes. (These are discussed in more detail later.) Novice is especially user friendly, and sufficient references can be retrieved to satisfy basic needs. The user is also guided in advancing to the next level of access. One can easily switch from one mode to another (by pressing the Spacebar); this is very convenient since the search strategy can be carried over to a more advanced mode. Expert uses a set-searching mode, which is useful for users familiar with the traditional command-line format. Although the mode does seem unfamiliar at first, the user will master the set-searching techniques easily; in fact the mode sometimes proves more effective than Dialog's command search mode.

Although there are no tutorials included on the CD-ROM, South African studies has extremely useful and friendly online help which is context-sensitive. Help is accessed by F1. The directions are clear, including examples, and are fortunately far more user friendly than the manual. (A basic test of user-friendliness is to see how far one can go using only online help, without having to resort to the manual.) Detailed explanations are given in the online help - including how to leave help and how to proceed. The command function $(F 8)$ is also context-sensitive. When on a display screen, the commands relating to display, printing and downloading are displayed, which is a very positive feature.

Users need to know what is happening (e.g. while the database is being searched), and be able to interrupt or to exit the program easily (e.g. if a search is not proceeding according to expectations). While printing and downloading, the record numbers being printed or downloaded are flashed, which is very useful. However, there is no indication of computing progress during a search process (e.g. $20 \%$ or $60 \%$ of the search completed), which makes it difficult to decide if interruption is necessary. The manual suggests that most searches require less than 30 seconds to complete, but should it be necessary to stop a search in progress, Control and Break pressed together will terminate the search and allow you to continue.

There are different opinions about the importance of response time. Válas (1994:211) remarks:

'A retrieval system may be as user friendly as you wish, but you will not like it if one single search step in an intricate query may take two hours and displaying the hits may take another two, or if complicated search strategies are not possible at all'.

No problems were experienced with response time, although NISC admits that for special retrieval functions, the reaction time will be a bit slower.

NISC's software provides clear instructions (at the bottom of the screen) on how to proceed, and these can be supplemented by using the online help. The user of NISC discs can be assured of clear and helpful directions, with distinct and friendly error messages. At the novice search screen, for example, a message appears encouraging the user to combine search terms with the AND or NOT operators (OR is the default operator, automatically inserted between search terms in the same field). Should there be an inadequate search result, the user is advised to use truncation and then directed accordingly. A further example: with a null (0) result, F1 provides guidance on how to adapt the search strategy.

Users should be able to navigate through screens with the minimum of effort and keystrokes. Navigation is easy in South African studies. Gaining initial access is simple, selecting the search mode and switching modes is easy, as is quitting the program. NISC software is consistent in the use 
of keys, for example $\mathrm{F} 1$ is pressed for more information or to display online help (depending on the situation). The Up and Down arrows are used to move between fields on the search screen, as well as between records displayed. The PageUp and PageDown keys display the previous or next record (this takes getting used to). When displaying records, one can move to a specific record by pressing F7. The Home and End keys can be used to move to the beginning or end of long records. Escape is used to modify a search after displaying records, to clear a screen, or to quit the program.

Movement from screen to screen is easy. There are, however, small things that one must become accustomed to, such as NISC's particular use for the PageUp and PageDown keys. Sometimes it is a bit tedious getting more information, but with 15 options on F9 one has to accept that not all can be displayed where one might require them on a present screen and that further information will therefore be at least two keystrokes away.

A useful feature of South African studies is that it provides details necessary for document delivery from some of the database producers. On the second introductory screen, the telephone, fax and e-mail particulars are listed for three database producers: State Library, NELM and NALN. Document delivery details are also indicated as part of many complete bibliographic records, for example all records retrieved from the $S A N B$ and ISAP databases have detailed document delivery particulars, and many records from Knipkat have a field listing NALN's fax number.

At present it is not possible to link retrieved references from South African studies with indications of own library holdings, but NISC is investigating this possibility.

\section{Searching and search management}

The three search modes (novice, advanced and expert) support different levels of sophistication. The space bar is used to toggle between search modes. The novice mode is exceptionally user friendly. It provides the basic search field (title, abstract and key terms), the author field, year of publication field, as well as a field to limit the search to a specific database (e.g. NELM - Literary awards). By default, all of the databases are searched together.

The novice mode provides guidelines on searching (e.g. using Boolean operators and truncation) which can prepare the novice user to move to the advanced level - an important feature. The advanced mode provides access to all the fields. Fields applying to specific databases only are indicated as such (e.g. Journal [ISAP/NELM; Directors [IG]). For both the novice and advanced search modes, the user is prompted to complete a form - thus encouraging the refinement of search strategies by searching in more than one field. Although it is easy to upgrade from a search mode (the search history is 'copied' to the next level of access), it is not possible to downgrade to a lower search level if the present search level proves to be too advanced. When combining information in more than one field in the advanced mode, a message appears in a field connector box, outlining the search fields (e.g. AUTHOR and BASIC SEARCH and PUB. YEAR).

Boolean logic (AND, OR, NOT), proximity operators (NEARx, ADJx), nesting (the use of brackets to group search terms) and truncation can be used in all three search modes. Different fields can also be combined by means of Boolean operators. Two types of truncation are provided for, namely * for multicharacters and ? for a single character. The * can be used for right as well as embedded truncation. Furthermore, various options are provided for range searching for example 1978-1982, 1978 to 1982 , or 1978 thru 1982. The year can also be truncated to retrieve everything from a specific decade, for example 198?. Clear instructions for range searching are provided in the online help. The same applies for help on the other search fields.

The expert search mode supports interactive set searching. The user specifies the fields, search terms and other search criteria. Although the expert mode appears awesome at first sight, it is actually very user friendly (and powerful). Fields can be specified by using field codes, and sets for search statements can be combined. The latter is useful since it is not necessary to retype complicated search statements. The most important field codes are indicated at the bottom of the screen, while the rest are accessible via F7. The search history is displayed in a separate column, making it easy to monitor progress, and to adapt search strategies.

The selection of search terms is enhanced by the use of the AUTODEX $^{\mathrm{TM}}$ (automatic index). The AUTODEX ${ }^{\mathrm{TM}}$ for a field pops up automatically when starting to type. It features an index for words (e.g. distance) or phrases (e.g. distance education, or distance education colleges) and highlights the closest matching term in the index. The indexes can be browsed (using the arrow keys), and words and phrases can conveniently be pasted by pressing the Insert key.

The EXPANDED AUTODEX ${ }^{\mathrm{TM}}$ is available on pressing F2, providing a wider working area for viewing a search field's index. The number of records containing a search term, and the number of occurrences of a term, are indicated alongside the term. Terms can be tagged (by pressing the Tab key) before pasting the search string by pressing the Insert key thus saving unnecessary typing or keystrokes.

A ROTATED INDEX is provided in the expert mode. This is a permuted phrase index which reacts to any word in the search statement on pressing the Shift and F2 keys. The selected term and all narrower terms are indicated (e.g. libraries and different types of libraries). Terms can be selected and pasted.

An option is provided for automatic plural searching; this can be switched on or off as desired. The P.I.C. ${ }^{\text {TM }}$ Variant software, which handles all known variations of English spelling of terms, as well as differences in using compound words, is used. For example, fiber glass, behavior, color and paleonto$\log y$ will retrieve records which have any of the other forms of the words, in addition to any singular or plural forms. This feature is especially important in South Africa where both 
English and American spelling is used, and where users are not necessarily searching in their mother tongues.

Apart from the AUTODEX ${ }^{\mathrm{TM}}$ which can be used for browsing terms in each field, NISC software allows lateral searching. This is a very useful feature, allowing the user to select terms from the display of either the index or records which have already been retrieved and used automatically as search terms, without further need to enter the terms. The AUTODEX $^{\mathrm{TM}}$, EXPANDED AUTODEX ${ }^{\mathrm{TM}}$, ROTATED INDEX and lateral searching are all very helpful, especially since South African studies does not include an online thesaurus. (There are, however, other NISC products with online thesauri.)

The author index also proves most useful, but remember not to use commas when typing the author's name. This gives a null result without any warning or advice on not using commas to separate the surname and initials. The help function, however, does explain that one must avoid punctuation here.

The default for word order is varied; this can be changed to exact order. Varied allows, for example, for the retrieval of both 'online searching' and 'searching online'.

For each search statement the number of records retrieved for individual terms, as well as the total number of records retrieved, are displayed. If there is a null result, the user is prompted to use F1 (help) - a very handy feature for enhancing search results and improving users' search skills. Editing of search statements is simple, especially in the expert mode. The arrow keys are used to make changes, or to move to a previous search statement, edit and repeat it. Search strategies can be saved, including the search statement, date and a short description. Search strategies can be loaded for updating (e.g. for a current awareness service) or deleted when obsolete. When printing or downloading the search strategy, record numbers and the date of the search can be included.

In anthologies like South African studies, there are bound to be duplicate records. NISC solves the problem of duplication among files by creating composite records containing information shared by two or more source records, plus any data that is unique to a record.

\section{Output}

When displaying records, the search terms are highlighted. Having the field names in different colours enhances the readability of the text. One can enable lateral searching while displaying records, and it is also possible to search for specific text in a record or move to the next or previous highlighted term. This is especially handy in long records. Records can be sorted according to title, author, degree, date, language and database - in ascending or descending order. The only option which might create a problem is sorting according to the language field, since the index in this field includes irrelevant terms (e.g. values such as art, best, and peoples names).
The search output can be displayed on screen, printed or downloaded. There are two fixed formats, one short and one long. The default short format displays the title of publication and, if applicable, the journal title. (The default format may, however, be altered.) The long format displays a complete record. To toggle between the two formats the Enter key is pressed. Customized formats are also available. The record format (e.g. ASCII, DBase III, delimited and fixed fields), fields and labels may be specified. The two fixed print formats and customized formats apply to printing and downloading. A friendly feature is that when completing the printing options, a message warns that the display format will be used. This provides the opportunity of changing the display format, for example from short to long.

A quick print option allows a record displayed on screen to be printed. When selecting quick print, the user is prompted to choose between printing and downloading. The printing options also apply to downloading. Both downloading and printing are very quick and convenient. Apart from doing a screen dump (quick print), or printing or downloading all records, records can also be selected by marking. Marking and unmarking records by using the tag and untag option (i.e. by pressing the Tab key) is most convenient. All records can be tagged (and untagged), but it is also possible to specify particular record numbers for tagging. When printing or downloading, a range of records can also be specified; these will be added to records already marked. An appropriate message warns that marking a range of records will add the range to records already tagged.

\section{Database content}

Information on each of the 11 databases, their scope, coverage, and currency is available in the introductory screens. Although a lot of useful detail is given, the database producers have provided no information on their indexing policies nor on other important details, such as lists of journals which have been indexed. (Other NISC discs for example, have journal details.) Ali (1990:29) stresses the general lack of information on database policies - an aspect which limits experienced searchers in their use of the databases.

Aspects that may be considered with regard to database quality include the availability of abstracts and descriptors, spelling mistakes and typographical errors, inconsistent indexing policy, thesaurus quality and selective indexing of titles. The authors came across several problems in these areas (e.g. spelling/typographical errors), but an investigation of these aspects would require a separate evaluation. Since these issues reflect on the database producers (i.e. not on NISC SA) and will naturally vary for a composite CD-ROM, they are not dealt with in this article. 


\section{Conclusion}

NISC's ROMWRIGHT ${ }^{\mathrm{TM}}$ software on South African studies meets with the requirements for user friendliness and supports effective information retrieval. The software is both powerful and convenient to use, and the online help, user support and guidance are exemplary.

There is a great attraction in having the 11 local databases available in one source, especially major bibliographic control tools like ISAP and SANB. ISAP especially will be a drawcard for subscribing to South African studies, and this will enable a wider market to become familiar with some of the lesser known databases on the disc. There are valuable files on South African studies which were previously not easily accessible, like the NELM databases which provide some fascinating references for users searching in the South African-English literature field.

There are unique problems which manifest with anthology CD-ROMs. For example, the various databases on South African studies do not all include the same fields (e.g. fields such as awards, sponsors, award descriptions are limited to some databases). Another example: the databases are not solely English based; it is possible to search using both English and Afrikaans terminology. (Knipkat and Index to South African theses and dissertations, for example, make use of Afrikaans descriptors). Producer inconsistencies in the treatment of documents in languages other than English might mislead the user to assume that all relevant articles were retrieved. (To illustrate this: A search in the title field on biblioteke, biblioteek retrieved several titles not retrieved when searching under librar* in the title field.) These problems should not negatively influence retrieval, as long as users are aware of differing indexing policies. Afrikaans/ English variants and Afrikaans plurals require more attention - something to which NISC SA has already agreed. NISC's positive attitude in improving this feature is also evident in its encouragement to users to bring spelling variations or uses of compound terms to its attention. NISC SA has shown itself to be open to criticisms, having appreciation for suggestions and passing these on to NISC for consideration in the software and manual.

The number of individual databases included on the CDROM has already increased since the first edition was published, and NISC SA continue negotiating for further databases. Our overall impression is that South African studies is a very attractive product which library and information services of any size in the Southern African subregion will eventually find indispensable. It deserves a wide market both locally and internationally.

\section{References}

Ali, S.N. 1990. Retrieval commands of CD-ROM databases: a comparison of selected products. CD-ROM professional, 3(5):28-33.

Andrews, C. 1990. Understanding CD-ROM software. CD-ROM professional, 3(4):59-62.
Armstrong, C.J. 1995. Database information quality. Library \& information briefings, 62(July):1-14.

Bosch, V.M. \& Hancock-Beauliey, M. 1995. CDROM user interface evaluation: the appropriateness of GUIS. Online \& CDROM review, 19(5):255-270.

Clement, E. 1994. Wilson indexes on CD-ROM: a comparison of WILSON-DISC and SilverPlatter. CD-ROM professional, 7(1):155-157.

Crampton, M. 1995. Publishing your database on CDROM for profit: the FISHLIT and NISC experience. The electronic library, 13(5):453-457.

Duszak, Z. \& Koczkodaj, W.W. 1994. A consistency-driven approach to CD-ROM selection. Library software review, 13(4):260-268.

Foulds, M.S. \& Foulds, L.R. 1990. CD-ROM disk selection and evaluation. Reference services review, 18(2):27-38.

Fourie, I. 1993. ERIC op CD-ROM. Deel 2: Kriteria vir vergelyking. SAIBI-nuusbrief, 13(2):5.

Haar, J., Clark, J., Jacobs, S. \& Campbell, F. 1990. Choosing CDROM products: a selection checklist for CD-ROM collection development. College and research libraries news, 51(9):839841.

Harry, V. \& Oppenheim, C. 1993a. Evaluations of electronic databases, part 1: criteria for testing CDROM products. Online and CDROM review, 17(4):211-222.

Harry, V. \& Oppenheim, C. 1993b. Evaluation of electronic databases, part II: testing CDROM products. Online \& CDROM review, 17(6):339-368.

Hartley, R.J. 1989. LISA on CD-ROM: an evaluation. Online review, 13(1):53-56.

Herther, N.K. 1988. How to evaluate reference material on CDROM. Online, 12(2):106-108.

Johnson, D. 1991. CD-ROM selection and acquistion in a network environment. Computers in libraries, 11(9):17-22.

Johnston, C.S. 1994. CD-ROM database quality: some observations based on experience at Sultan Qaboos University library. Program, 28(4):379-394.

Maes, V. 1995. Currency of information found in SilverPlatter's MEDLINE CDROM. Online \& CDROM review, 19(2):59-69.

Miller, D.C. 1987. Evaluating CDROMs: to buy or what to buy. Database, 10(2):36-42.

Nicholls, P., Han, I., Stafford, K. \& Whitridge, K. 1990. A framework for evaluating CD-ROM retrieval software. Laserdisk professional, 3(2):41-46.

Nicholls, P.T. 1993. CD-ROM buyer's guide \& handbook. 3rd edition. Wilton, CT: Eight Bit Books.

Richards, T. 1995. A comparative evaluation of four leading CDROM retrieval software packages. Computers in libraries, 15(4): 70-75.

Richards, T. \& Robinson, C. 1993. Evaluating CD-ROM software: a model. CD-ROM professional, 6(9):92-101.

Rowley, J.E. 1993. Selection and evaluation of software. Aslib proceedings, 45(3):77-81

Rowley, J. 1995. Human/computer interface design in Windowsbased CD-ROMs: an early review. Journal of librarianship and information science, 27(2):77-87.

Schwartz, C. 1993. Evaluating CD-ROM products: yet another checklist. CD-ROM professional, 6(1):87-91.

Sievert, M.C. \& Sievert, D.E. 1991. Online searching in philosophy: a comparison of Philosopher's index and FRANCIS. Online review, 15(2):63-76.

Snyman, D. 1993. Kriteria vir die evaluering van inligtingherwinning uit databasisse in leeskompakskyfformaat. Mousaion, 11(1):46-59. 
Speight, S. 1996. Evaluating CD-ROM products. Managing information, 3(12):36-38.

Trenner, L. 1987. How to win friends and influence people: definitions of user-friendliness in interactive computer systems. Journal of information science, 13:99-107.

Válas, G. 1994. Comparison of some widespread CDROM information retrieval software packages. Online \& CDROM review, 18(4):211-221.

Van der Merwe, D. 1993. The Jutastat CD-ROM database on Statutes and Law Reports. Tydskrif vir hedendaagse RomeinsHollandse reg, 56(3):531-536.
Van der Walt, H.E.A. \& Van Brakel, P.A. 1991. Metode vir die bepaling van die herwinningseffektiwiteit van 'n bibliografiese databasis inleeskompakskyfformaat. Suid-Afrikaanse tydskrif vir biblioteek-en inligtingkunde, 59(1):32-42.

Van Stuywenberg, Y.B. 1993. Effektiwiteit van die herwinningsprogrammatuur van leeskompakskyfdatabasisse. M Bibl-verhandeling, Randse Afrikaanse Universiteit, Johannesburg.

Vickery, B. \& Vickery, A. 1993. Online search interface design. Journal of documentation, 49(2):103-187.

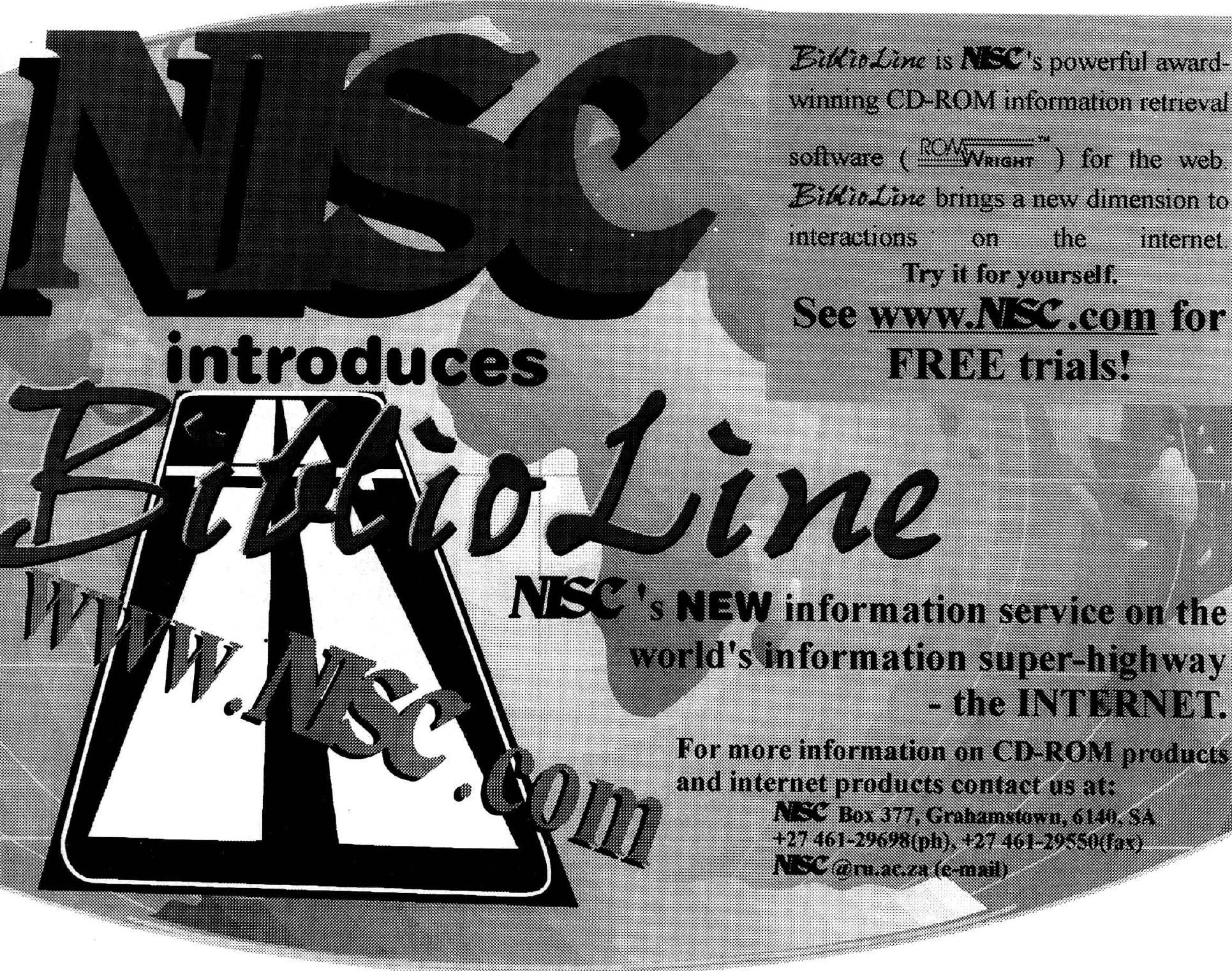

